\title{
The Associations Between the Maladaptive Personality Dimensions of Neediness and Self-Criticism, Defense Styles, Selfobject Needs, and Attachment Styles in an Iranian Sample
}

\author{
Shima Tondar, MA \\ Islamic Azad University, Science and Research Branch and Vira \\ Psychology Clinic, Tehran, Iran \\ Shima Shakiba, Phd \\ University of Social Welfare and Rehabilitation Sciences and \\ Vira Psychology Clinic, Tehran, Iran
}

\author{
Rui C. Campos, Phd \\ University of Évora
}

Asghar Dadkhah, Phd

University of Social Welfare and Rehabilitation Sciences

\author{
Sidney J. Blatt, Phd \\ Yale University
}

\begin{abstract}
The present study extends previous findings by examining whether defense styles, selfobject needs, attachment styles relate to Neediness and Self-Criticism, as maladaptive personality dimensions focused, respectively, on relatedness and self-definition in an Iranian sample. Three hundred and 52 participants completed a sociodemographic questionnaire as well as the Persian forms of the Depressive Experiences Questionnaire, Experience of Close Relationships-Revised, Defense Style Questionnaire, Beck Depression Inventory—-II and Selfobject Needs Inventory. Two multiple linear regression analyses, entering Self-criticism and Neediness as criterion variables, were computed. According to the results, high attachment anxiety, high immature defenses, high depressive symptoms, and high need for idealization were related to self-criticism, and explained $47 \%$ of its variance. In addition, high attachment anxiety, low mature defenses, high neurotic defenses, high avoidance of mirroring, and low avoidance of idealization/twinship were related to neediness, and explained $40 \%$ of its variance. A principal components analysis was performed, entering all the studied variables. Three factors emerged; 1 describing a maladaptive form of psychological functioning and 2 describing more mature modes of psychological functioning. The results are discussed in their implications for the understanding of neediness and self-criticism as maladaptive personality dimensions focused, respectively, on relatedness and self-definition.
\end{abstract}

Keywords: neediness, self-criticism, attachment styles, defense styles, selfobject needs

According to Blatt's model (1974, 2004, 2008), interpersonal relatedness and self-definition play a crucial role in the process of personality development. Interpersonal relatedness refers to a process by which a person establishes and maintains mature, reciprocal, and mutual satisfying relationships with others. Selfdefinition is related to the development of a positive, differentiated, and integrated sense of identity. An integration of interpersonal relatedness and self-definition is essential for an optimal development and for psychological and physical well- being (Blatt \& Zuroff, 1992). Differences in the relative emphasis that individuals put in the processes of relatedness and self-definition define two basic personality styles with specific modes of cognition, coping, and defense strategies. But an excessive emphasis on each of the two processes/dimensions specifies two maladaptive personality dimensions (dependency/ neediness, self-criticism) or two forms of vulnerability to distress and psychopathology, especially depression (Blatt, 2004, 2008; Blatt \& Shichman, 1983).
Shima Tondar, MA, Department of Clinical Psychology, Islamic Azad University, Science and Research Branch, and Vira Psychology Clinic, Tehran, Iran; Rui C. Campos, Phd, Department of Psychology, School of Social Sciences and Research Center on Education and Psychology (CIEP), University of Évora; Shima Shakiba, Phd, Department of Clinical Psychology, University of Social Welfare and Rehabilitation Sciences, and Vira Psychology Clinic; Asghar Dadkhah, Phd, Department of Counseling, University of Social Welfare and Rehabilitation Sciences; Sidney J. Blatt, Phd, Department of Psychology, Yale University.
Sidney J. Blatt deceased on May 11, 2014. The inclusion of Dr. Blatt as a senior co-author is a way of honoring him. In some way, he was a mentor of the project that resulted in the present paper.

This article is based in part on Shima Tondar's master's thesis in clinical psychology under the supervision of Rui C. Campos. We thank all participants in this study.

Correspondence concerning this article should be addressed to Shima Tondar, Department of Clinical Psychology, Islamic Azad University, Science and Research Branch, Tehran, Iran. E-mail: s.tondar.psy@gmail .com or shima.tondar@viraclinic.com 